\title{
HIGHER PREVALENCE OF NEPHROPATHY IN YOUNG ROMA FEMALES COMPARED WITH NON-ROMA FEMALES
}

\author{
Jaroslav Rosenberger ${ }^{1,2,3}$, Mária Majerníková ${ }^{1,3}$, Peter Jarčuška5, Daniel Pella ${ }^{5}$, Mária Mareková6, \\ Andrea Madarasová Gecková, 3,4, Monika Halánová2; HepaMeta Team* \\ ${ }^{1}$ Fresenius Medical Care - Dialysis Services, Pieštany, Slovakia \\ 2Department of Public Health, Faculty of Medicine, P. J. Šafárik University in Košice, Košice, Slovakia \\ ${ }^{3}$ Graduate School Košice Institute for Society and Health, P. J. Šafárik University in Košice, Košice, Slovakia \\ ${ }^{4}$ Olomouc University Social Health Institute, Palacký University in Olomouc, Olomouc, Czech Republic \\ ${ }^{5} 1$ st Department of Internal Medicine, P. J. Šafárik University in Košice, Faculty of Medicine and L. Pasteur University Hospital, Košice, Slovakia \\ ${ }^{6}$ Department of Medical and Clinical Biochemistry and LABMED, Faculty of Medicine, P. J. Šafárik University in Košice, Košice, Slovakia
}

\section{SUMMARY}

Objectives: Ethnic differences in the prevalence of various chronic diseases, including end-stage renal disease, have been previously reported. Surprisingly, data focusing on the lower grade of chronic kidney disease (CKD) are scarce. Thus, the aim of this study was to explore differences in the prevalence of nephropathy between the Roma and non-Roma populations.

Methods: Data from the cross-sectional population based HepaMeta study conducted in Slovakia were used. Nephropathy was defined as: a known history of any kidney disease; or the presence of proteinuria/hematuria; or glomerular filtration rate (GFR) $<60 \mathrm{ml} / \mathrm{min}$. The odds ratio for the prevalence of nephropathy was calculated using binary logistic regression.

Results: In an age-adjusted model, Roma females had OR of 1.56 for having nephropathy over non-Roma females (OR 1.56; $95 \% \mathrm{Cl} 1.01-2.42$; $p<0.05$ ). In addition, Roma females had a significantly lower GFR (mean difference $3.4 \mathrm{~m} / \mathrm{min}, \mathrm{t}=-3.58, p<0.001$ ); all female patients with proteinuria were Roma.

Conclusions: This cross-sectional study on the young general population found that Roma females have half-higher odds for nephropathy than non-Roma females. Therefore, to prevent risks we should focus on searching for ethnic, social and medical determinants of CKD. Interventions to decrease the incidence of CKD in the target population should also address ethnic inequalities as well as female gender.

Key words: ethnicity, Roma, nephropathy, chronic kidney disease, gender differences

Address for correspondence: J. Rosenberger, Fresenius Medical Care - Dialysis Services Slovakia, Tr. SNP 1, 04011 Košice, Slovakia. E-mail: rosenberger.jaroslav@gmail.com

\section{INTRODUCTION}

Chronic kidney disease (CKD) is becoming a public threat due to high mortality, morbidity and costs associated with it (1-4). According to Levey et al., at least $12 \%$ of the US population suffer from CKD (5). The exact prevalence of CKD in Slovakia has not yet been explored; in a report from the National Center for Health Information the total number of patients examined in any nephrology out-patient department during the year 2011 was more than $8 \%(6)$.

Incidence of CKD in African Americans is 2-3 times higher compared with Caucasian Americans (7). A similar variance in the incidence of CKD is found in India compared with Europe (8) and across European countries (4). These differences were reported in well-being status, and their impact on various chronic diseases has been shown as well $(4,9-13)$. Some of them could be attributed

\footnotetext{
*HepaMeta Team members are listed in Appendix
}

to genetic predisposition, others to modifiable health-risk factors or access to health care $(11,14)$.

Regarding racial and ethnic differences, Roma are the major ethnic minority in Slovakia and as in the Czech Republic, Hungary and Romania this ethnicity represents an appreciable proportion of the overall population (15). Several reports found associations between lower socioeconomic status, decreased health-related quality of life and higher prevalence of cardiovascular risk factors among Roma compared with non-Roma $(9,12,13)$. Thus far, studies focused on cardiovascular morbidity and mortality have shown a higher risk of death in Roma when controlled for socioeconomic status (16). A recent report by Kol'vek et al. suggests that Roma have 2.85-times higher risk of prevalence of end-stage renal disease (ESRD) compared with non-Roma (17).

However, the comparison of CKD prevalence among Roma and the general population of Slovakia has not yet been studied. Therefore, the aim of this study was to explore the differences in the prevalence of nephropathy between Roma and non-Roma population. 


\section{MATERIALS AND METHODS}

Data from the cross-sectional HepaMeta study conducted in Slovakia in 2011 were used. The sample consisted of 452 Roma (mean age $=34.7 ; 35.2 \%$ men) and 403 non-Roma (mean age $=33.5 ; 45.9 \%$ men) respondents. Roma in selected settlements were recruited by local Roma community workers. Respondents from the major population were randomly selected from a list of patients from general practitioners. Data were collected via questionnaire, anthropometric measures and analysing blood samples. The methodology is described elsewhere (18).

\section{Statistical Analysis}

Differences in nominal variables were explored using the $\chi^{2}$-test; while the t-test was used to explore differences in age and GFR between Roma and non-Roma. The odds ratio for the prevalence of nephropathy was calculated using binary logistic regression; the analysis was controlled by age and stratified by gender. The Statistical Package for the Social Science (IBM SPSS Inc. Chicago, IL, USA) version 20 was used for statistical analyses.

\section{RESULTS}

The mean age of the subjects was $34.1 \pm 8.4$ years, 344 were males (40.2\%). Proteinuria was detected in 11 subjects (1.3\%), hematuria in 113 subjects (13.2\%), GFR $<60 \mathrm{ml} / \mathrm{min}$ in only 4 subjects $(0.5 \%)$, and the mean GFR was $84 \pm 12 \mathrm{ml} / \mathrm{min}$. The prevalence of nephropathy as defined in the Methods section was thus $15.9 \%$ (136 subjects).

452 out of 855 subjects (52.9\%) were Roma. There was a higher proportion of Roma females in the sample (293 Roma females vs. 218 non-Roma females; $\chi^{2}=10.2, \mathrm{p}<0.001$ ) and Roma were significantly older (mean difference 1.2 years, $t=-2.03$, $\mathrm{p}<0.05$ ) (Table 1).

The prevalence of nephropathy in the total sample with regard to ethnicity is presented in Table 1 . The prevalence of nephropathy was higher in Roma than in non-Roma (OR 1.66; 95\% CI $1.14-2.42 ; \mathrm{p}<0.01)$, similarly as the prevalence of proteinuria (OR 9.01; 95\% CI 1.16-71.36; $\mathrm{p}<0.05$ ), and hematuria (OR 1.83; 95\% CI 1.21-2.76; $\mathrm{p}<0.01)$.

Table 1. Description of the sample

\begin{tabular}{|l|c|c|}
\hline & Roma (N=452) & Non-Roma (N=403) \\
\hline $\begin{array}{l}\text { Mean age (standard deviation) } \\
\text { in years }\end{array}$ & $34.7(9.1)$ & $33.5(7.3)$ \\
\hline Male & 159 & 185 \\
\hline Female & 293 & 218 \\
\hline Hematuria & 74 & 39 \\
\hline Proteinuria & 10 & 1 \\
\hline $\begin{array}{l}\text { Mean GFR (standard deviation) } \\
\text { in ml/min }\end{array}$ & $84(13)$ & $83(12)$ \\
\hline GFR <60 ml/s & 3 & 1 \\
\hline History of nephropathy & 9 & 10 \\
\hline
\end{tabular}

As there was a statistically significant difference in gender and age, we stratified the sample by gender and controlled analysis by age. In the age-adjusted model, Roma females had 56\% higher odds for having nephropathy than non-Roma females (OR 1.56; 95\% CI 1.01-2.42; $\mathrm{p}$ 0.05). In addition, Roma females had significantly lower GFR (mean difference $3.4 \mathrm{ml} / \mathrm{min}, \mathrm{t}=-3.58$, $\mathrm{p}<0.001$ ); all 6 female patients with proteinuria were Roma (not significant). There were no differences in the prevalence of nephropathy in Roma males compared with non-Roma males (Table 2).

\section{DISCUSSION}

In this study we explored ethnic differences in the prevalence of nephropathy between Roma and non-Roma populations. Roma ethnicity is associated with a $6.6 \%$ higher prevalence of nephropathy compared with non-Roma. The differences are striking among females (17.9\% for non-Roma vs. $25.6 \%$ for Roma), with the odds for having nephropathy half-higher in Roma females than in non-Roma females. Similar to our findings, other studies explored also the fact that ethnic inequalities in Roma females compared with non-Roma females work together as a fundamental cause of poor well-being and are believed to increase their higher risk of illness $(19,20)$.

Surprisingly, information about relevant prevalence of CKD in Roma across Europe is scarce. Recently, a Bulgarian study exploring the prevalence of CKD and its risk factors among 365 Roma and 1,261 non-Roma (21) was presented in poster form during a major European nephrology event. The authors showed the higher prevalence of albuminuria and/or decreased GFR in Roma (18.7\%) compared with the non-Roma population. Roma ethnicity was associated with $7.3 \%$ higher frequency of CKD compared with the non-Roma population. The results are similar to our ones, despite their patients being older and with higher morbidity. However, the authors did not control their results for age or gender. On the other hand, they controlled the sample by socioeconomic status, arterial hypertension, overweight and obesity (21). With regards to CKD, Molnár et al. have also shown that Roma kidney transplant recipients are at higher risk of mortality and worse graft outcomes independent of several sociodemographic and clinical determinants (14).

Until now, data about ESRD have been available only in Slovakia; thus, "the tip of the iceberg" has already been explored: Kolvek et al. (17) found 1.34-times higher prevalence of ESRD in Roma. Approximately one-third of the entire Slovak dialysis population was explored, and the share of Roma among this dialysed population was $11.6 \%$. At the time of dialysis initiation they were 10 years younger than non-Roma, and they more often

Table 2. Prevalence of nephropathy in the sample (403 nonRoma and 452 Roma)

\begin{tabular}{|l|c|c|c|c|c|c|}
\hline \multirow{2}{*}{ Gender } & \multicolumn{2}{|c|}{ Non-Roma } & \multicolumn{2}{c|}{ Roma } & \multicolumn{2}{c|}{ Cohort sample } \\
\cline { 2 - 7 } & $\mathrm{n}$ & $\%$ & $\mathrm{n}$ & $\%$ & $\mathrm{~N}$ & $\%$ \\
\hline Male & 11 & 5.9 & 11 & 6.9 & 22 & 6.4 \\
\hline Female $^{*}$ & 39 & 17.9 & 75 & 25.6 & 114 & 22.3 \\
\hline Cohort sample $^{*}$ & 50 & 12.4 & 86 & 19.0 & 136 & 15.9 \\
\hline
\end{tabular}

*statistically significant difference between non-Roma and Roma 
suffered from diabetic nephropathy. When age-adjusted, RR for ESRD was 2.85-times higher in Roma than in non-Roma (17). According to these findings, Kolarčik et al. emphasised health interventions targeted on adolescent Roma, because their poor health is likely to lead to poor health in adulthood (13). Thus, our results, together with findings of Kol'vek et al. (17) and Kolarčik et al. (13), may help to promote preventive measures and to reduce CKD morbidity risk in Roma.

\section{Strengths and Limitations}

This study was strictly focused on the prevalence of CKD in Roma compared with non-Roma according to known risk factors (defined as history of any kidney disease, decreased GFR, and the presence of proteinuria or hematuria).

The design of this study has some limits to be mentioned. First, this is cross-sectional observational study and therefore we cannot predict how the observed pathologic indicators will evolve during the subsequent period. Because the observed population was relatively young (in their thirties), we can expect the prevalence of arterial hypertension and diabetes mellitus as well as the complications of these two diseases including CKD to rise. A second weakness of this study is the diagnostic utility. The HepaMeta study was not designed as nephrological; we assessed the presence of nephropathy mainly by using a dip-stick, which is cheap and simple method, but one with a low specificity, mainly when considering hematuria. Some cases of hematuria could be attributed to non-nephrologic bleeding (e.g. menstruation), others to non-progressive causes (e.g. uncomplicated cystitis), but many are false positive findings due to the use of certain drugs or consumption of certain foods (e.g. mangold). Transient hematuria is common (39\% in the general population), but persistent hematuria (defined as urine positive in two out of three consecutive dipsticks, e.g. over a one to two weeks period) is estimated to occur in just $2.5-4.3 \%$ of adults seen in primary care. In clinical practice hematuria should be confirmed by urinary sediment evaluation and/or urinary tract imaging (22).

\section{Policy Implications}

The presented results showing a higher prevalence of nephropathy in the young Roma population may provide us with "clues" for better observations, deeper preventive diagnostic procedures and relevant treatment interventions to prevent the progression of CKD. However, this study shows that the prevalence of nephropathy is mostly diagnosed due to hematuria, which could also be related to urinary or gynaecologic infections or other non-progressive "benign" lesions. For further research the measurement of albuminuria from the first morning void should be more specific.

\section{Recommendations for Further Research}

Our findings imply that Roma have a higher prevalence of nephropathy. The result must be verified in a longitudinal prospective study with a specific diagnostic utility, in line with up-to-date knowledge about the higher prevalence of CKD in Roma. Further studies should be carried out to shed more light on this important pathway. The risk of pathways encompassing ethnic differences
(Roma vs. non-Roma) and the mentioned diagnostic determinants (as albuminuria, arterial hypertension, diabetes mellitus, nutrition status) should be studied as well.

\section{CONCLUSION}

The current cross-sectional study found in the young general population that Roma females have half-higher odds for nephropathy than non-Roma females. Therefore, we should focus on searching ethnic, social and medical determinants of CKD to prevent the risks. Interventions to decrease CKD incidence should also address ethnic inequalities as well as female gender.

\section{Acknowledgement}

This project was partially supported by the Agency of the Slovak Ministry of Education for the Structural Funds of EU, project CEMIOITMS: 26220120058 (40\%). This paper was also partially funded within the framework of the project "Social determinants of health in socially and physically disadvantaged and other groups of population" (CZ.1.07/2.3.00/20.0063) and by Roche Slovensko, s.r.o.

\section{Conflict of Interests}

None declared

\section{APPENDIX}

HepaMeta Team: Peter Jarčuška, Andrea Madarasová Gecková, Mária Mareková, Daniel Pella, Leonard Siegfried, Pavol Jarčuška, Lýdia Pastvová, Ján Fedačko, Jana Kollárová, Peter Kolarčik, Daniela Bobáková, Zuzana Veselská, Ingrid Babinská, Sylvia Dražilová, Jaroslav Rosenberger, Ivan Schréter, Pavol Kristian, Eduard Veselíny, Martin Janičko, Ladislav Virág, Anna Birková, Marta Kmet’ová, Monika Halánová, Darina Petrášová, Katarína Cáriková, Viera Lovayová, Lucia Merkovská, Lucia Jedličková, Ivana Valková

\section{REFERENCES}

1. Abecassis M, Bartlett ST, Collins AJ, Davis CL, Delmonico FL, Friedewald JJ, et al. Kidney transplantation as primary therapy for end-stage renal disease: a National Kidney Foundation/Kidney Disease Outcomes Quality Initiative (NKF/KDOQITM) conference. Clin J Am Soc Nephrol. 2008 Mar;3(2):471-80.

2. Wolfe RA, Ashby VB, Milford EL, Ojo AO, Ettenger RE, Agodoa LY, et al. Comparison of mortality in all patients on dialysis, patients on dialysis awaiting transplantation, and recipients of a first cadaveric transplant. N Engl J Med. 1999 Dec 2;341(23):1725-30.

3. Ruggenenti P, Cravedi P, Remuzzi G. Mechanisms and treatment of CKD. J Am Soc Nephrol. 2012 Dec;23(12):1917-28.

4. Zoccali C, Kramer A, Jager KJ. Chronic kidney disease and end-stage renal diseasea - a review produced to contribute to the report 'the status of health in the European union: towards a healthier Europe'. NDT Plus. 2010;3(3):213-24.

5. Levey AS, Stevens LA. Estimating GFR using the CKD Epidemiology Collaboration (CKD-EPI) creatinine equation: more accurate GFR estimates, lower CKD prevalence estimates, and better risk predictions. Am J Kidney Dis. 2010 Apr;55(4):622-7.

6. National Health Information Center. Nephrology care and renal replacement therapy in the Slovak Republic 2011. Edition health statistics, no. 31. Bratislava: National Health Information Center; 2012. (In Slovak.) 
7. Collins AJ, Foley RN, Herzog C, Chavers B, Gilbertson D, Ishani A, et al. Excerpts from the United States Renal Data System, 2008 Annual Data Report: Atlas of chronic kidney disease \& end-stage renal disease in the United States, National Institutes of Health NIDDK/DKUHD. Am J Kidney Dis. 2009;53(1):S1-S374.

8. Agarwal SK, Srivastava RK. Chronic kidney disease in India: challenges and solutions. Nephron Clin Pract. 2009;111(3):c197-203.

9. Skodova Z, van Dijk JP, Nagyova I, Rosenberger J, Ondusova D, Studencan M, et al. Psychosocial factors of coronary heart disease and quality of life among Roma coronary patients: a study matched by socioeconomic position. Int J Public Health. 2010 Oct;55(5):373-80.

10. Dorkova Z, Sopkova Z, Tkacova R. "CEM" risk factors and severity of obstructive sleep apnoea in central European Roma and non-Roma patients referred for a diagnostic polysomnography. Int J Public Health. 2010 Oct;55(5):429-34. Erratum in: Int J Public Health. 2010 Oct;55(5):517.

11. Reijneveld SA. Ethnic differences in health and use of health care: the questions to be answered. Int J Public Health. 2010 Oct;55(5):353-5.

12. Kolarčik P, Geckova AM, Orosova O, van Dijk JP, Reijneveld SA. Predictors of health-endangering behaviour among Roma and non-Roma adolescents in Slovakia by gender. J Epidemiol Community Health. 2010 Dec;64(12):1043-8.

13. Kolarcik P, Madarasova Geckova A, Orosova O, van Dijk JP, Reijneveld SA. To what extent does socioeconomic status explain differences in health between Roma and non-Roma adolescents in Slovakia? Soc Sci Med. 2009 Apr;68(7):1279-84.

14. Molnar MZ, Langer RM, Remport A, Czira ME, Rajczy K, KalantarZadeh K, et al. Roma ethnicity and clinical outcomes in kidney transplant recipients. Int Urol Nephrol. 2012 Jun;44(3):945-54.
15. Vokó Z, Csépe P, Németh R, Kósa K, Kósa Z, Széles G, et al. Does socioeconomic status fully mediate the effect of ethnicity on the health of Roma people in Hungary? J Epidemiol Community Health. 2009 Jun;63(6):455-60.

16. Sudzinova A, Nagyova I, Studencan M, Rosenberger J, Skodova Z, Vargova $\mathrm{H}$, et al. Roma coronary heart disease patients have more medical risk factors and greater severity of coronary heart disease than non-Roma. Int J Public Health. 2013 Jun;58(3):409-15

17. Kolvek G, Rosicova K, Rosenberger J, Podracka L, Stewart RE, Nagyova I, et al. End-stage renal disease among Roma and non-Roma: Roma are at risk. Int J Public Health. 2012 Aug;57(4):751-4.

18. Madarasová Gecková A, Jarčuška P, Mareková M, Pella D, Siegfried L, Jarčuška P, et al.; HepaMeta Team. HepaMeta - Prevalence of hepatitis $\mathrm{B} / \mathrm{C}$ and metabolic syndrome in population living in separated and segregated Roma settlements: a methodology for a cross-sectional populationbased study using community-based approach. Cent Eur J Public Health. 2014 Mar;22 Suppl:S6-11.

19. Janevic T, Jankovic J, Bradley E. Socioeconomic position, gender, and inequalities in self-rated health between Roma and non-Roma in Serbia. Int J Public Health. 2012 Feb;57(1):49-55.

20. Carrasco-Garrido P, López de Andrés A, Hernández Barrera V, JiménezTrujillo I, Jiménez-García R. Health status of Roma women in Spain. Eur J Public Health. 2011 Dec;21(6):793-8.

21. Krivoshiev S, Koteva A, Kraev Z, Mihaylov G, Shikov P. Screening for chronic kidney diseases in Roma people in Bulgaria. Nephrol Dial Transplant. 2012;27 Suppl 2:130-1.

22. Jimbo M. Evaluation and management of hematuria. Prim Care. 2010 Sep;37(3):461-72. 